CORRECTION

\title{
Correction to: Fluoxetine incentivizes ventral striatum encoding of reward and punishment
}

Vincent D. Costa (iD) and Bruno B. Averbeck

This is a U.S. government work and not under copyright protection in the U.S.; foreign copyright protection may apply 2022

Neuropsychopharmacology (2022) 47:1281; https://doi.org/10.1038/s41386-021-01194-0

Correction to: Neuropsychopharmacology https://doi.org/10.1038/ s41386-021-01012-7, published 29 April 2021
In this article the spelling of Dr. Pasquereau's name was given incorrectly.

The original article has been corrected 